\title{
Data report: specific surface area and physical properties of subsurface basalt samples from the east flank of Juan de Fuca Ridge ${ }^{1}$
}

Mark E. Nielsen ${ }^{2}$ and Martin R. Fisk ${ }^{2}$

\section{Chapter contents}

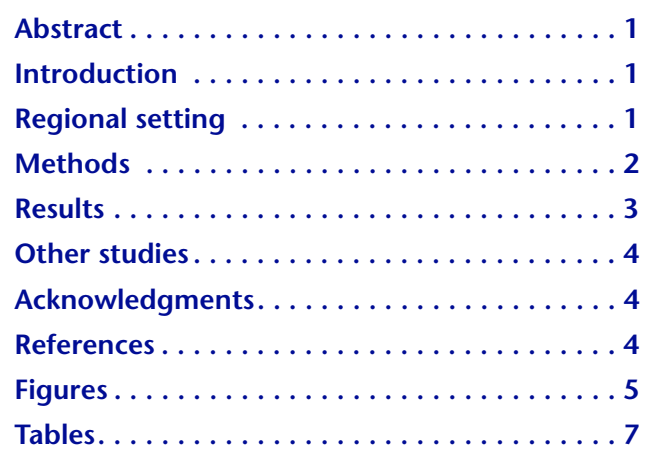

${ }^{1}$ Nielsen, M.E., and Fisk, M.R., 2008. Data report: specific surface area and physical properties of subsurface basalt samples from the east flank of Juan de Fuca Ridge. In Fisher, A.T., Urabe, T., Klaus, A., and the Expedition 301 Scientists, Proc. IODP, 301: College Station, TX (Integrated Ocean Drilling Program Management International, Inc.). doi:10.2204/iodp.proc.301.205.2008

${ }^{2}$ College of Oceanic and Atmospheric Sciences, 104 Ocean Administration Building, Oregon State University, Corvallis OR 97331, USA.

Correspondence author:

mnielsen@coas.oregonstate.edu

\section{Abstract}

Specific surface area (SSA) was measured on 13 samples of basalt recovered from Integrated Ocean Drilling Program Expedition 301 Hole U1301B drilled on the east flank of Juan de Fuca Ridge. SSA ranged from 0.3 to $52 \mathrm{~m}^{2} / \mathrm{g}$. SSA is positively correlated with porosity and inversely correlated with bulk density and $P$-wave velocity. Excluding two breccia samples (with SSAs of 29 and 52 $\mathrm{m}^{2} / \mathrm{g}$ ), the average SSA was $2.3 \mathrm{~m}^{2} / \mathrm{g}$.

\section{Introduction}

As seawater circulates through the ocean crust, it dissolves igneous minerals, precipitates secondary minerals, and exchanges cations and anions with crustal rocks. One factor that determines bulk rates of such reactions is the specific surface area (SSA) (Hodson, 1999). SSA is defined as the area per unit mass of a sample and has units of $\mathrm{L}^{2} / \mathrm{M}$ (e.g., $\mathrm{m}^{2} / \mathrm{g}$ ). It is commonly measured on laboratory prepared powdered, crushed, or granular material used in dissolution/alteration studies. Although SSA of igneous minerals has been reported (e.g., Brantley and Mellott, 2000), there are no reported values for subsurface marine basalt, the most common rock type of Earth's crust.

In this investigation we present the first reported values of SSA for rock samples recovered from the ocean crust. We selected 13 samples from a short vertical section of igneous rock from a borehole drilled on the east flank of Juan de Fuca Ridge. Bulk density, porosity, $P$-wave velocity, and degree of alteration were measured at sea, and SSA was measured in a shore-based laboratory.

\section{Regional setting}

Integrated Ocean Drilling Program (IODP) Expedition 301 was the first part of a multiexpedition program to assess hydrogeologic conditions on the east flank of Juan de Fuca Ridge. Investigations included determining formation-scale fluid pathways; establishing links between fluid circulation, alteration, and microbiological processes; and determining relationships between seismic and hydrologic anisotropy. Knowing the SSA of the ocean crust is a potentially key parameter of this study. The deepest core of the expedition was in Hole U1301B $\left(47^{\circ} 45.228^{\prime} \mathrm{N}, 127^{\circ} 45.827^{\prime} \mathrm{W}\right)$. It penetrated $583 \mathrm{~m}$ below the seafloor (318 $\mathrm{m}$ into basement), and 
it is from this hole that we obtained samples (see the "Expedition 301 summary" chapter).

The study site is on a sedimented ridge flank with a basement age of 3-5 Ma (see the "Expedition 301 summary" chapter). A total of $69.1 \mathrm{~m}$ of core was recovered from the interval from 351 to 583 meters below seafloor (mbsf). Three principal rock types were identified: (1) mixed basalt and hyaloclastite breccia, (2) aphyric to highly phyric pillow basalt, and (3) massive basalt. Each of these rock types was represented in our samples for SSA analysis (Table T1).

Pillow basalt was the dominant lithology recovered. Pillows contained 1\%-5\% round gas vesicles and were slightly to moderately altered. Alteration in the pillow units included vesicle fill, vein formation, and replacement of olivine phenocrysts. Massive basalts were indicated by units of constant lithology as long as $4.5 \mathrm{~m}$. They ranged from sparsely to highly vesicular with vesicles up to $3 \mathrm{~mm}$ in diameter. Massive basalt units contained fewer fractures and veins than the pillow basalts, allowing better core recovery and the retrieval of individual pieces as long as $94 \mathrm{~cm}$. Similar to the pillow basalts, alteration of the massive unit consists of vesicle fill, vein formation, and replacement of olivine phenocrysts. Recovery of basalt-hyaloclastite breccia was limited $(<1 \mathrm{~m})$, but this might reflect the fragility of the material rather than its low abundance in the stratigraphic column. Compositions of representative pillow and massive samples are given in Table T2.

\section{Methods}

A total of 83 samples were collected from Hole U1301B for shipboard determination of physical properties. Analyses included bulk density, grain density, porosity, thermal conductivity, and seismic velocity, but not all measurements were made on each sample. Physical properties were measured on cubes (usually $2 \mathrm{~cm}$ on a side) cut from larger pieces of the core. After being measured on the ship, the cubes were transferred to our laboratory for SSA measurement of 13 selected samples. The selected samples spanned the range of depth and the range of shipboard physical properties.

\section{Physical property methods}

Methods for physical property analyses are presented in detail in the "Methods" chapter and are briefly summarized here. Bulk density, grain density, and porosity properties are measured by resaturating samples in natural seawater under a partial vacuum for $24 \mathrm{~h}$ and then weighing them to obtain a wet mass. Samples are dried in an oven for $24 \mathrm{~h}$ at $105^{\circ} \mathrm{C}$ and then a dry mass is obtained. Sample volume is measured using a Quantachrome gas pycnometer (using He). Density and porosity properties can be calculated from these three measurements plus an assumed salinity of the resaturation water. Seismic velocity was measured using a $P$-wave logger system (Hamilton frame PWS-3). Samples were resaturated under a partial vacuum in seawater for at least $2 \mathrm{~h}$, and then they were sanded, polished, and ultrasonically cleaned. The compressional wave velocity calculation is based on the delay time of a $500 \mathrm{kHz}$ square wave signal traveling between a pair of piezoelectric transducers in contact with opposing surfaces of the sample cube.

\section{Surface area measurement}

The standard method for measuring SSA is by gas adsorption and the application of the Brunauer, Emmett, and Teller (BET) equation (Brunauer et al., 1938), which is described in detail in a number of reference books (e.g., Gregg and Sing, 1982; Lowell and Shields, 1991; and Condon, 2006). The principle of BET analysis is that at low relative pressure, gas adsorbs to a solid in a monolayer (multilayers form at higher pressures). By knowing the number of gas molecules in a monolayer and the dimensions of an individual molecule, the surface area covered by the monolayer can be calculated (see Table T3 for an example). The BET equation models a measured number of moles of adsorbate (n) adsorbed on $1 \mathrm{~g}$ of sample with the following relationship (Rouquerol et al., 1994):

$$
\frac{P / P_{0}}{n\left(1-P / P_{0}\right)}=\frac{1}{n_{m} C}+\frac{c-1}{n_{m} C}\left(P / P_{0}\right)
$$

where

$$
\begin{aligned}
n_{\mathrm{m}}= & \text { calculated number of moles adsorbed as a } \\
& \text { monolayer on } 1 \mathrm{~g} \text { of adsorbent } \\
P= & \text { gas pressure } \\
P_{0}= & \text { saturation vapor pressure of the gas, and } \\
c= & \text { a constant that is dependent upon the shape } \\
& \quad \text { of the isotherm. }
\end{aligned}
$$

We used an instrument with a volumetric approach (ASAP 2000, Micromeritics, USA) so $n_{\mathrm{m}}$ is obtained by plotting $P / V_{\mathrm{a}}\left(P_{0}-P\right)$ against $P / P_{0}$, where $V_{\mathrm{a}}$ is the volume of gas adsorbed per gram of sample normalized to standard temperature and pressure (STP) $\left(\mathrm{cm}^{3} / \mathrm{g}\right)$. Generally the plot is linear at low relative pressures $\left(P / P_{0}<0.3\right)$. The slope of the linear part of the graph has a slope $(s)$ of $c-1 / V_{\mathrm{m}} c$ and an intercept (i) of $1 / V_{\mathrm{m}} c$, where $V_{\mathrm{m}}$ is the volume of gas required to form a monolayer on a unit gram of the sample $\left(\mathrm{cm}^{3} / \mathrm{g}\right)$. Both $s$ and $i$ have units of $\mathrm{cm}^{3} / \mathrm{g}$ at STP. By algebraic substitution, $V_{\mathrm{m}}=(s+i)^{-1}$. Finally, the BET SSA can be calculated with the equation 


$$
\mathrm{SSA}=\frac{L V_{\mathrm{m}} a_{\mathrm{m}}}{V_{l}}
$$

where

$$
\begin{aligned}
a_{\mathrm{m}}= & \text { area occupied by a molecule of the adsorbate } \\
& \left(1.49 \times 10^{-19} \mathrm{~m}^{2}\right. \text { for Ar), } \\
L= & \text { Avogadro's number, and } \\
V_{1}= & \text { molar volume of the analysis gas ( } 22 \mathrm{~L} \text { for } \mathrm{Ar}) \\
& \text { at STP. }
\end{aligned}
$$

The $8 \mathrm{~cm}^{3}$ cubes $(2 \mathrm{~cm} \times 2 \mathrm{~cm} \times 2 \mathrm{~cm})$ used for shipboard physical property measurements were too large to fit in standard BET analysis tubes, which have an $11 \mathrm{~mm}$ opening. Therefore, we sectioned the samples into a few rectangular blocks (minimum dimension $\leq 7.5 \mathrm{~mm}$ ) with a rock saw to allow them to pass through the analysis tube openings. In order to remove cutting debris and precipitated salt, sectioned samples were ultrasonically cleaned, resaturated with deionized water under a partial vacuum for $24 \mathrm{~h}$, and then dried at $105^{\circ} \mathrm{C}$ for $72 \mathrm{~h}$. Samples were placed in acetone-rinsed tubes and then degassed under a partial vacuum at $150^{\circ} \mathrm{C}$ for $24 \mathrm{~h}$ (until the system pressure dropped below $1.3 \mathrm{kPa}$ ). Sample size was limited by the size of the degassing station heating element. In each case, we used the maximum amount of sample that could be uniformly heated by the element, which was generally $\sim 6 \mathrm{~g}$. After degassing, samples were immediately analyzed using $\mathrm{N}_{2}$ or $\mathrm{Ar}$ as the adsorbate. Both gases have similar physical properties and are commonly used to make surface area measurements (Gregg and Sing, 1982). Ar is a slightly smaller molecule and has a lower vapor pressure. Analyses performed with Ar, with lower vapor pressure, result in a smaller dead space correction; Ar is therefore used for materials with small surface areas because it is more sensitive than $\mathrm{N}_{2}$ (Anbeek, 1992; Sing et al., 1985). Although Ar measurements are generally more precise, they are not necessarily more accurate because the molecules may interact with the sample differently. Therefore, we present values derived from both gases. Multipoint surface area (five points) was calculated for relative pressures $\left(P / P_{0}\right)$ ranging from 0.058 to 0.225 . All samples were measured at least twice to confirm repeatability of adsorption isotherms; some were measured as many as four times. A commercially prepared kaolinite sample was periodically run as a standard.

\section{Results}

Table T1 summarizes the results of $\mathrm{N}_{2}$ and Ar analyses. One sample was only analyzed with $\mathrm{N}_{2}$, five were analyzed with both gases, and seven were only analyzed with Ar. In our samples, SSAs measured with Ar were smaller than those measured with $\mathrm{N}_{2}$ for the same samples, and replicates measured with Ar had a smaller standard deviation, so that adsorbate was preferentially used. For samples that were measured with both adsorbates, SSA using Ar was roughly 50\% of the value measured with $\mathrm{N}_{2}$, which is consistent with previously reported differences between $\mathrm{N}_{2}$ and Kr (Anbeek, 1992; Brantley and Mellott, 2000). The SSAs of the 12 samples analyzed with Ar ranged from 0.3 to $52 \mathrm{~m}^{2} / \mathrm{g}$. The samples represent three lithologies: breccia (two samples), pillow basalt (seven samples), and massive flow (three samples). The two breccia samples (mean SSA $=40.5 \pm 16.3 \mathrm{~m}^{2} / \mathrm{g}$ ) were highly altered and had a significantly higher SSA than the pillow and flow basalt samples (mean SSA = $2.3 \pm 1.6 \mathrm{~m}^{2} / \mathrm{g}$ ).

Figure $\mathbf{F} 1$ shows a typical plot of the adsorption and desorption isotherms from our samples. Because of instrument limitations, we obtained desorption isotherms only for samples analyzed with $\mathrm{N}_{2}$. The combination of isotherm shape and hysteresis is an indicator of mesoporosity: pore diameters between 2 and $50 \mathrm{~nm}$ (Gregg and Sing, 1982; Rouquerol et al., 1994; Sing et al., 1985). The hysteresis loop matches type $\mathrm{H} 3$ and was observed for all samples for which we obtained desorption data, which is characteristic of slit-shaped pores or platelike particles. The low-pressure hysteresis $\left(P / P_{0}<0.4\right)$ is unusual and does not generally occur in laboratory ground samples. It is probably because of the long run time for these samples ( $13 \mathrm{~h}$ per sample) and the fact that liquid nitrogen used to cool the samples would evaporate over time. As recommended by Gregg and Sing (1982), we checked the repeatability of all our measurements to ensure that no changes were occurring to our samples because of the adsorption procedure. Figure F1 illustrates the repeatability of measurements for the sample from Section 301-U1301B-3R-1 using both nitrogen and argon.

Figure F2 shows the correlations between SSA and three physical properties and sample depth. The strongest correlation is with porosity $\left(R^{2}=0.73, P \leq\right.$ $0.05)$, which shows a positive, roughly linear trend. There are also qualitative negative correlation relationships between SSA and bulk density and between SSA and seismic velocity. The sample from Section 301-U1301B-18R-2 was collected from a vesicular massive unit and had the second highest porosity of all our samples but had a lower than average BET SSA and was only lightly altered (Table T1). We interpret this as evidence that BET SSA is independent of macroscale porosity such as vesicles and instead is controlled by increased porosity because of secondary mineral formation. The same sample also appeared to be an outlier in the correlation of BET SSA with 
bulk density and $P$-wave velocity. Although not quantitative, increased BET SSA correlates with increased alteration in all the physical property plots.

\section{Other studies}

Our data fall in the range of previously reported data for basalt gravel; $1 \mathrm{~m}^{2} / \mathrm{g}$ for crushed samples (Stevens and McKinley, 2000) and $11.5 \mathrm{~m}^{2} / \mathrm{g}$ for a $2-6 \mathrm{~mm}$ size fraction (Tokunaga et al., 2003). Brady and Gíslason (1997) report a value of $0.2 \mathrm{~m}^{2} / \mathrm{g}$ for a $75-125$ $\mu \mathrm{m}$ size fraction of seafloor basalt that was ground in the laboratory for dissolution experiments. Brantley and Mellott (2000) report SSA for various grain sizes of feldspar, olivine, and pyroxene, all of which are present in our bulk rock samples. Surface areas of these minerals range from 0.02 to $1.8 \mathrm{~m}^{2} / \mathrm{g}$, with the smallest size fractions having the largest SSA. Their higher values overlap with the range of values we obtained for bulk rocks (Table T1).

\section{Acknowledgments}

We are grateful to the Integrated Ocean Drilling Program and the scientists of Expedition 301 for the opportunity and support to collect these samples. Postcruise funding from United States Science Advisory Committee (USSAC) supported this research. Thanks also to G. Rorrer and L. Kabalnova for access and help in making the BET measurements.

\section{References}

Anbeek, C., 1992. Surface roughness of minerals and implications for dissolution studies. Geochim. Cosmochim. Acta, 56(4):1461-1469. doi:10.1016/00167037(92)90216-6

Brady, P.V., and Gíslason, S.R., 1997. Seafloor weathering controls on atmospheric $\mathrm{CO}_{2}$ and global climate. Geochim. Cosmochim. Acta, 615):965-973. doi:10.1016/ S0016-7037(96)00385-7
Brantley, S.L., and Mellott, N.P., 2000. Surface area and porosity of primary silicate minerals. Am. Mineral., 85(11-12):1767-1783.

Brunauer, S., Emmett, P.H., and Teller, E., 1938. Adsorption of gasses in multimolecular layers. J. Am. Chem. Soc., 60(2):309-319. doi:10.1021/ja01269a023

Condon, J.B., 2006. Surface Area and Porosity Determinations by Physisorption, Measurements and Theory: Amsterdam (Elsevier).

Gregg, S.J., and Sing, K.S.W., 1982. Adsorption, Surface Area and Porosity (2nd ed.): London (Academic Press).

Hodson, M.E., 1999. Micropore surface area variation with grain size in unweathered alkali feldspars: implications for surface roughness and dissolution studies. Geochim. Cosmochim. Acta, 62(21-22):3429-3435. doi:10.1016/ S0016-7037(98)00244-0

Lowell, S., and Shields, J.E., 1991. Powder Surface Area and Porosity (3rd ed.): New York (Chapman and Hall).

Rouquerol, J., Avnir, D., Fairbridge, C.W., Everett, D.H., Haynes, J.H., Pernicone, N., Ramsay, J.D.F., Sing, K.S.W., and Unger, K.K., 1994. Recommendations for the characterization of porous solids (technical report). Pure Appl. Chem., 66(8):1739-1758. doi:10.1351/ pac199466081739

Sing, K.S.W., Everett, D.H., Haul, R.A.W., Moscou, L., Pierotti, R.A., Rouquerol, J., and Siemieniewska, T., 1985. Reporting physisorption data for gas/solid systems with special reference to the determination of surface area and porosity (recommendations 1984). Pure Appl. Chem., 57(4):603-619. doi:10.1351/ pac198557040603

Stevens, T.O., and McKinley, J.P., 2000. Abiotic controls on $\mathrm{H}_{2}$ production from basalt-water reactions and implications for aquifer biogeochemistry. Environ. Sci. Technol., 34(5):826-831. doi:10.1021/es990583g

Tokunaga, T.K., Olson, K.R., and Wan, J., 2003. Moisture characteristics of Hanford gravels: bulk, grain-surface, and intragranular components. Vadose Zone J., 2(3):322329.

Initial receipt: 21 August 2007

Acceptance: 28 February 2008

Publication: 24 September 2008

MS 301-205 
Figure F1. A. Three nitrogen adsorption/desorption isotherms for a representative sample (Section 301U1301B-3R-1). Partial pressure is ratio of measured pressure to saturation vapor pressure of the gas. Hysteresis at intermediate to high pressure is consistent with a mesoporous sample with pore throats ranging from 2 to $50 \mathrm{~nm}$. Different symbols = repeat measurements to confirm that analysis was not causing irreversible changes to sample matrix. B. Two argon adsorption isotherms for the same sample. Note different scale on vertical axis. Full adsorption/desorption argon isotherms were not possible because of instrumental limitations. Argon isotherms had more pronounced bends compared to nitrogen isotherms. These bends indicate when a monolayer has formed and secondary layers subsequently begin forming. STP = standard temperature and pressure.

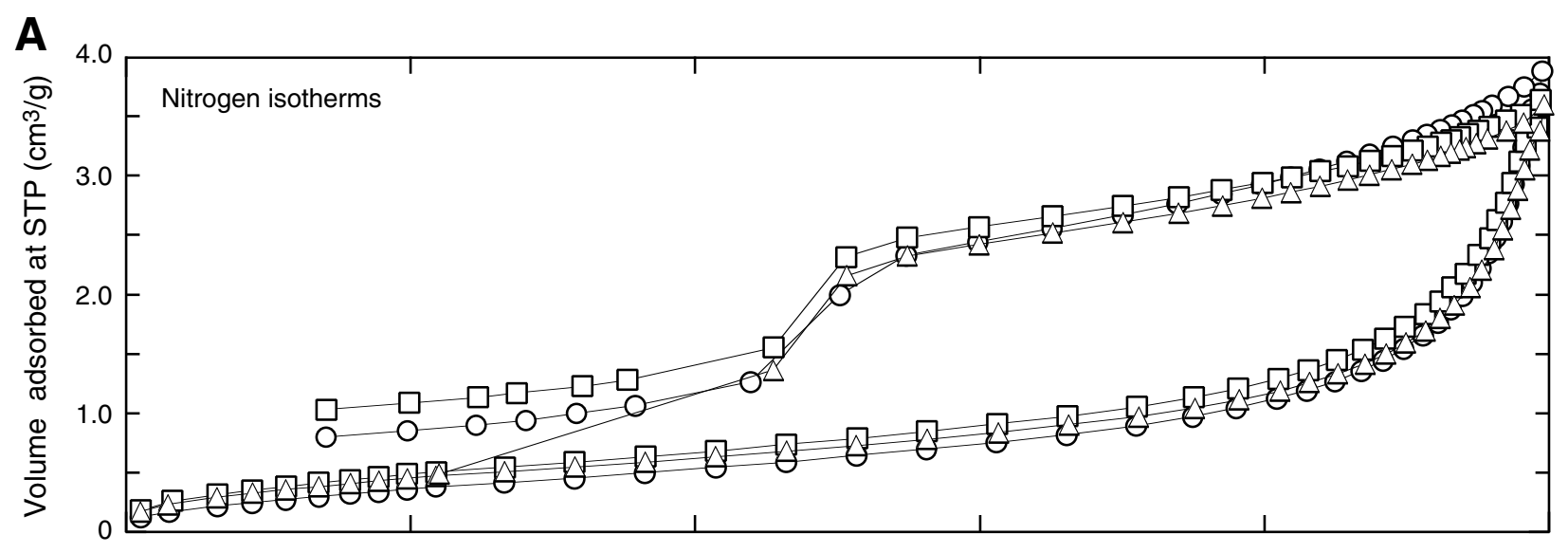

\section{B}

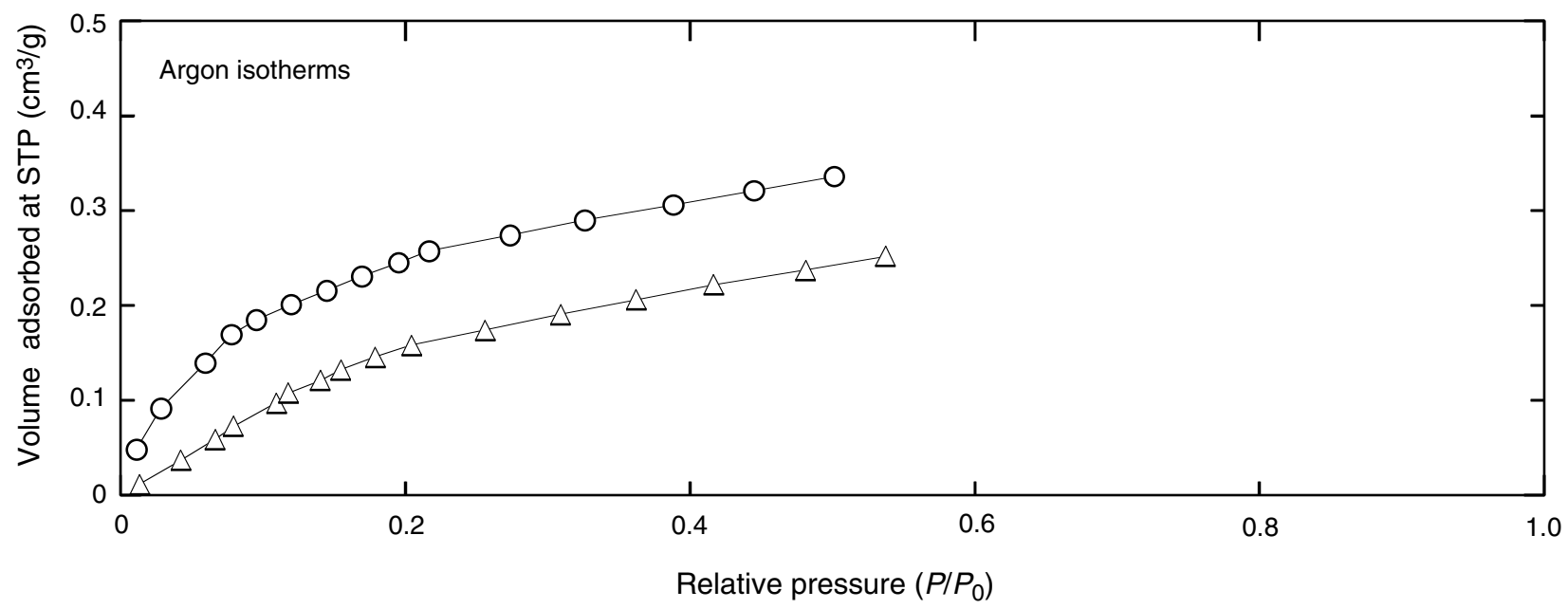


Figure F2. Crossplots of Brunauer, Emmett, and Teller (BET) specific surface area (SSA) with (A) sample depth and shipboard physical property measurements, (B) percent porosity, $(\mathbf{C})$ bulk density, and (D) $P$-wave velocity. Solid symbols $=$ BET measurements performed with nitrogen, open symbols $=$ BET measurements performed with argon. Larger graph shows data for pillow basalt and massive basalt samples. Insets show all data including two breccia samples. $P$-wave velocities were not measured on breccias.
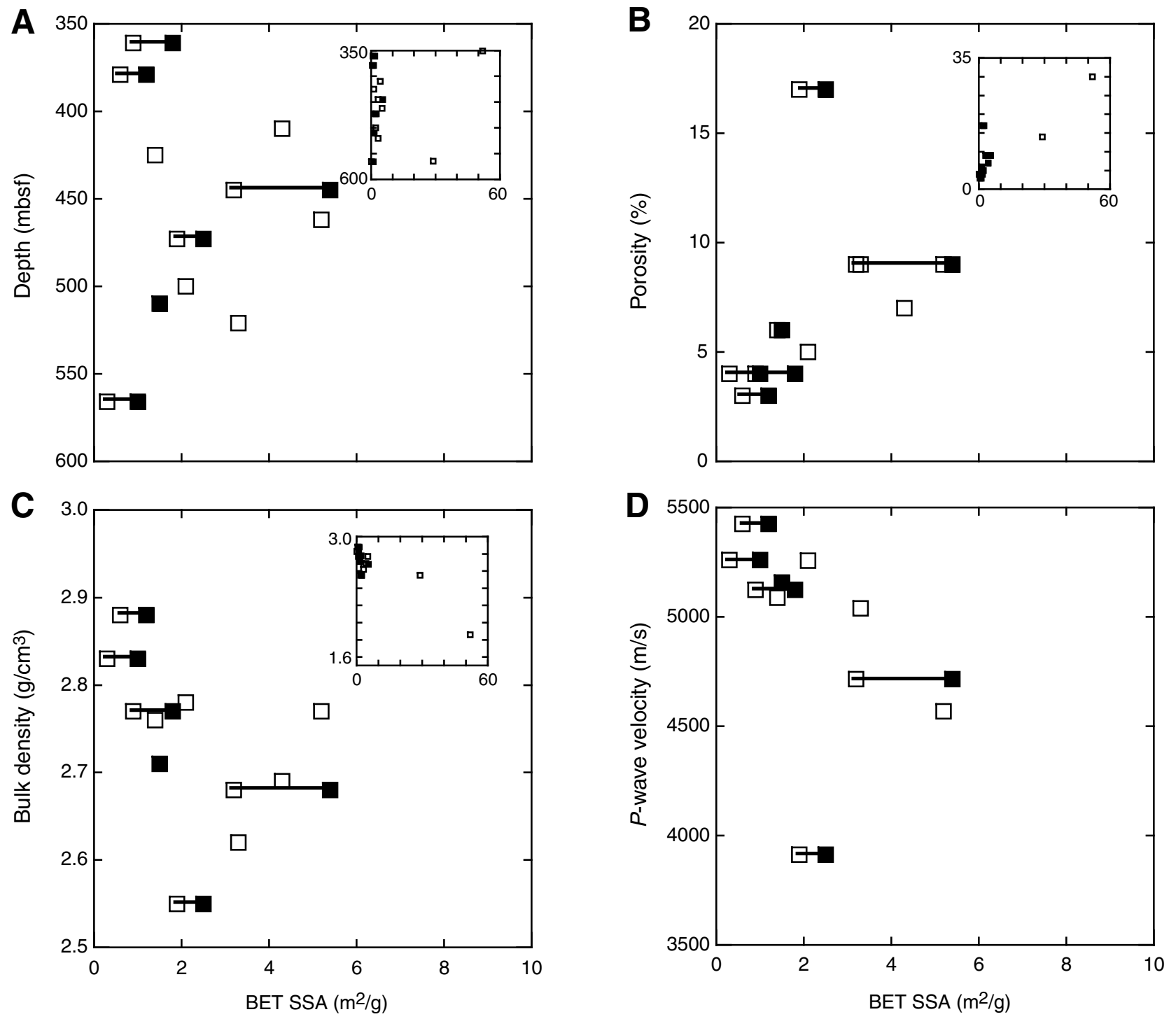


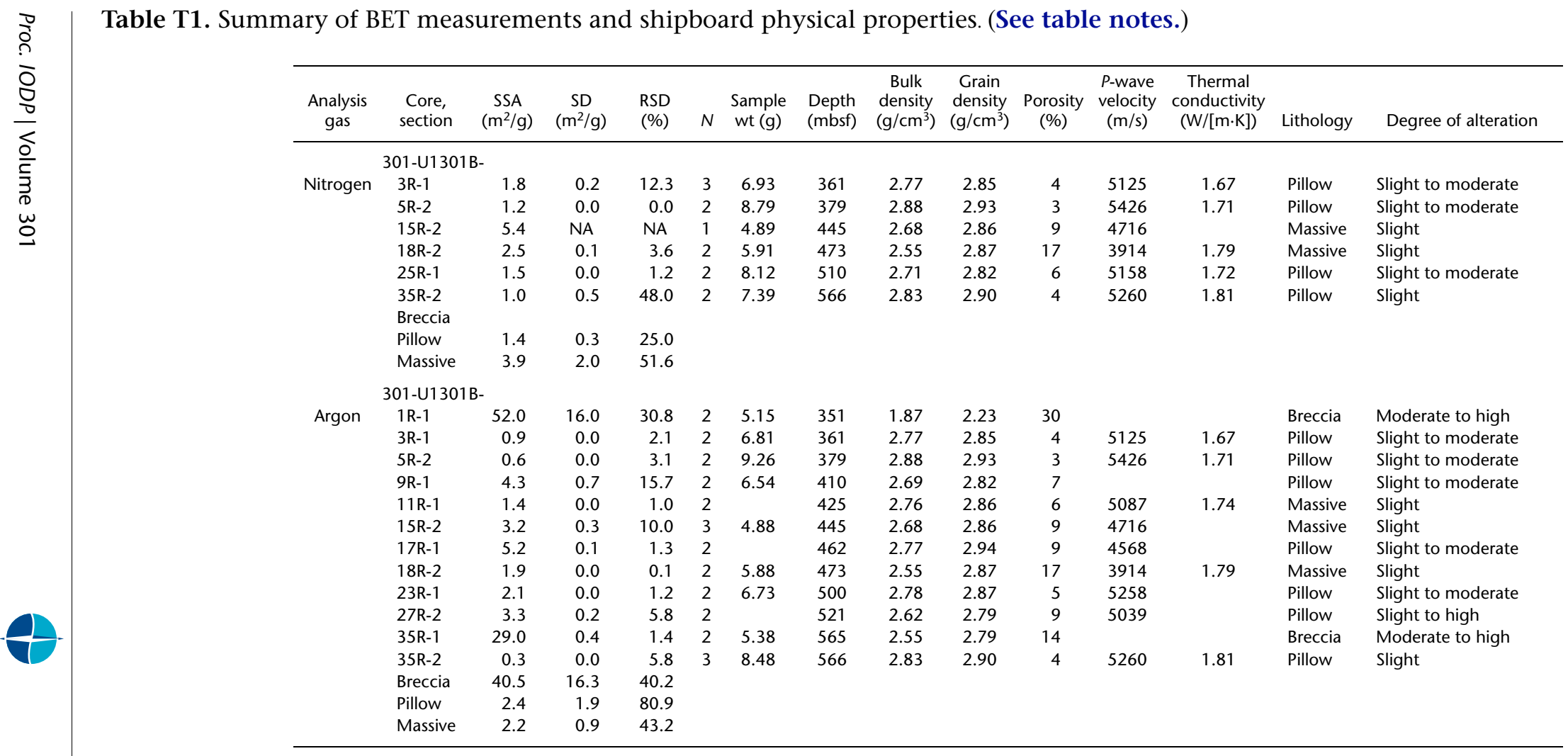

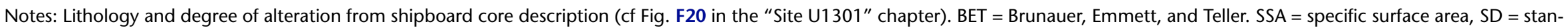
dard deviation, RSD = relative standard deviation, $N=$ number of replicates. Blank cells $=$ no measurements were made. 
Table T2. Summary of shipboard ICP-AES analyses. (See table notes.)

\begin{tabular}{lrr}
\hline & \multicolumn{2}{c}{ Major element oxide (wt\%) } \\
\cline { 2 - 3 } & \multicolumn{1}{c}{ Pillow } & \multicolumn{1}{c}{ Massive } \\
\hline $\mathrm{SiO}_{2}$ & \multicolumn{1}{c}{$49.82 \pm 0.77$} & $49.81 \pm 0.93$ \\
$\mathrm{Al}_{2} \mathrm{O}_{3}$ & $14.75 \pm 0.42$ & $13.94 \pm 0.54$ \\
$\mathrm{TiO}_{2}$ & $1.65 \pm 0.17$ & $1.98 \pm 0.29$ \\
$\mathrm{Fe}_{2} \mathrm{O}_{3}$ & $10.08 \pm 0.84$ & $11.98 \pm 1.04$ \\
$\mathrm{MgO}$ & $7.30 \pm 0.46$ & $7.21 \pm 0.43$ \\
$\mathrm{MnO}$ & $0.23 \pm 0.04$ & $0.18 \pm 0.03$ \\
$\mathrm{CaO}$ & $11.84 \pm 0.34$ & $11.04 \pm 0.71$ \\
$\mathrm{Na} 2 \mathrm{O}$ & $2.66 \pm 0.13$ & $2.81 \pm 0.27$ \\
$\mathrm{~K}_{2} \mathrm{O}$ & $0.12 \pm 0.08$ & $0.10 \pm 0.04$ \\
$\mathrm{P}_{2} \mathrm{O}_{5}$ & $0.14 \pm 0.02$ & $0.16 \pm 0.04$ \\
\hline
\end{tabular}

Notes: Data from Table T6 in the "Site U1301" chapter. Mean values based on 26 samples from pillow units and 6 samples from massive units. Samples from the breccia unit were not analyzed on board the ship. ICP-AES = inductively coupled plasma-atomic emission spectroscopy.

Table T3. Example of SSA calculation at STP, Section 301-U1301B-3R-1. (See table notes.)

\begin{tabular}{cccccccccc}
\hline Core, section & $\begin{array}{c}\text { Analysis } \\
\text { gas }\end{array}$ & $P / P_{0}$ & $\begin{array}{c}V_{\mathrm{a}} \\
\left(\mathrm{cm}^{3} / \mathrm{g}\right)\end{array}$ & $\begin{array}{c}P / V_{\mathrm{a}}\left(P_{0}-P\right) \\
\left(\mathrm{cm}^{3} / \mathrm{g}\right)\end{array}$ & $\begin{array}{c}\text { Slope } \\
\left(\mathrm{cm}^{3} / \mathrm{g}\right)\end{array}$ & $\begin{array}{c}\text { Intercept } \\
\left(\mathrm{cm}^{3} / \mathrm{g}\right)\end{array}$ & $R^{2}$ & $\begin{array}{c}V_{\mathrm{m}} \\
\left(\mathrm{cm}^{3} / \mathrm{g}\right)\end{array}$ & $\begin{array}{c}\text { SSA } \\
\left(\mathrm{m}^{2} / \mathrm{g}\right)\end{array}$ \\
\hline 301-U1301B-3R-1 & Argon & 0.059 & 0.140 & 0.453 & 4.018 & 0.200 & 0.998 & 0.24 & 0.9 \\
& & 0.078 & 0.169 & 0.498 & & & & & \\
& & 0.120 & 0.201 & 0.676 & & & & & \\
& & 0.170 & 0.231 & 0.883 & & & & & \\
& & 0.217 & 0.258 & 1.072 & & & & & \\
\hline
\end{tabular}

Notes: $a_{\mathrm{m}}=1.42 \times 10^{-19} \mathrm{~m}^{2}$ (from Lowell and Shields, 1991). $V_{1}=0.0222 \mathrm{~m}^{3}$ (calculated from density at standard temperature and pressure [STP]). $L=6.02 \times 10^{23}$. SSA = specific surface area. All results given at STP. 